\title{
OS DIREITOS HUMANOS INTERNACIONAIS E A VULNERABILIDADE DOS POVOS INDÍGENAS
}

\author{
INTERNATIONAL HUMAN RIGHTS OF INDIGENOUS PEOPLES AND \\ VULNERABILITY
}

${ }^{1}$ Keyla Cristina Farias dos Santos

\section{RESUMO}

Este artigo apresenta a democratização global para a proteção de minorias, através da promoção global dos Direitos Humanos. No plano do Direito Internacional dos Direitos Humanos, essas ideias estão na base do chamado processo de especificação dos sujeitos de direitos, segundo o qual, além de direitos gerais universais, extensíveis a todos, há necessidade de se reconhecer direitos específicos a determinados grupos vulneráveis dentro da sociedade. Isso com o objetivo de se atingir a igualdade real, ou pelo menos, reduzir as desigualdades de fato existente. Assim, a consolidação da proteção das minorias reflete a situação da necessidade do acesso à ordem jurídica justa de modo a garantir a efetividade de direitos fundamentais e a consolidação plena de acesso à justiça.

Palavras-chave: Proteção, Minorias, Efetividade, Justiça, Cidadania

\begin{abstract}
This paper presents the global democratization for the protection of minorities, through the global promotion of human rights. In terms of international human rights law, these ideas are the basis of the "specification process for the rights holder", according to which, in addition to general universal rights, extended to all, there is need to recognize specific rights to certain groups vulnerable in society. All this in order to achieve real equality, or at least reduce the existing fact of inequality. Thus, the consolidation of the protection of minorities reflects the situation of the need for access to the legal system just to ensure the effectiveness of fundamental rights and the full consolidation of access to justice.
\end{abstract}

Keywords: Protection, Minorities, Effectiveness, Justice, Citizenship

\footnotetext{
${ }^{1}$ Doutoranda em Direito pela Universidade Federal de Minas Gerais - UFMG, Minas Gerais (Brasil). Consultora na Câmara dos Deputados - Câmara Federal, Distrito Federal (Brasil). E-mail: keylafarias@ dir.dout.ufmg.br
} 


\section{INTRODUÇÃO}

O objetivo deste artigo consiste em analisar a proteção adequada das minorias na sociedade contemporânea, sendo que a proteção de Minorias é um dos temas mais complexos e controversos das Relações Internacionais. Teve seu auge no período entre- guerras, sob os auspícios da Liga das Nações. Depois da Segunda Guerra Mundial, o tema das minorias passou por um longo período de exclusão da agenda internacional, exclusão motivada, por um lado, em razão de posições congeladas pela Guerra Fria e, por outro, em função dos enfoques individual e universal dos direitos humanos, proclamados pela Declaração Universal dos Direitos Humanos. Foi somente o processo da descolonização, o qual, a partir do princípio da não-discriminação, impulsionou o ressurgimento tímido e esporádico do tema das minorias na agenda da Organização Mundial.

Os dramáticos acontecimentos subseqüentes à queda do Muro de Berlim e ao fim do bipolarismo no sistema internacional, com destaque à guerra na ex-Iugoslávia e aos conflitos na ex-União Soviética, decorrentes do colapso dos regimes autoritários nos países do Leste Europeu, deixaram a humanidade perplexa e chocada perante as dimensões de sua violência e das atrocidades cometidas. Esses eventos evidenciaram a urgente necessidade de um regime internacional eficaz de proteção de minorias, capaz de evitar que aspirações minoritárias se transformem em conflitos que ameacem não apenas a segurança nacional de Estados envolvidos, mas pondo igualmente em risco a segurança da própria comunidade internacional. É nesse contexto que se situa a concomitante retomada dos debates, no âmbito da ONU, acerca dos desafios colocados pela problemática da 'dinamite humana' - as minorias.

O presente estudo igualmente se propõe a verificar supostas manifestações, na recente abordagem da questão no âmbito da ONU, de tendências cada vez mais perceptíveis de democratização global que passaram a caracterizar o discurso global das Nações Unidas desde o fim da Guerra Fria. Os esforços em prol da democratização global repercutem no tratamento internacional da questão de minorias? Eis os questionamentos centrais a partir dos quais o presente trabalho procura analisar a atual abordagem da questão das minorias em nível global, avaliar sua natureza e identificar as perspectivas que oferece para lidar com o problema de minorias em prol da paz e da segurança num sistema internacional em transformação e sua interferência direta sobre às populações locais. 
O mesmo se diga da implementação de politicas universalistas, que não levam em conta as peculiaridades dos grupos vulneráveis existentes na sociedade. Levar a sério os direitos das minorias dependentes, sim, da combinação das duas vertentes da igualdade material, ou seja, depende, simultaneamente, da realização de politica de redistribuição e reconhecimento.

\section{OBJETIVOS}

O debate teórico acerca da questão das minorias apresenta-se como tema da maior atualidade e urgência na agenda internacional. Sua problemática, no entanto, é de longa data: seus aspectos centrais já foram debatidos na época da Liga das Nações, continuam polêmicos e ressurgem em discussões de problemas atuais das relações internacionais contemporâneas. Assim, convém citar, inter alia, a questão do paradigma de maior poder explicativo do fenômeno, o próprio conceito de Estado-Nação, o princípio de não- discriminação, a controvérsia acerca de medidas de discriminação positiva, implicando interpretações diferentes do princípio de igualdade (de jure vs. de fato), a questão da titularidade de direitos (individual vs. coletiva), os princípios da soberania (assim como sua gradual erosão) e da integridade territorial dos Estados, conflitando com reivindicações, por parte de grupos minoritários, de secessão e autodeterminação; e, sob um prisma mais amplo, questões tais como relações intergrupais e seu caráter potencialmente conflituoso.

A problemática das minorias é, sem dúvida, um tema muito amplo. A impressionante complexidade da questão também encontra expressão no seu caráter essencialmente interdisciplinar, o qual também a toma um objeto de estudo por excellence da disciplina das relações internacionais, uma vez que o debate teórico envolve, pelo menos, juristas, cientistas políticos, sociólogos, antropólogos, historiadores, filósofos e psicólogos; dificilmente as diversas abordagens logram não compenetrar nos campos de disciplinas afins.

A complexidade da problemática e os aspectos multidisciplinares da questão das minorias, ao passo que inviabilizam pretensões de exaustividade na abordagem, exigem, ao menos, uma clara delimitação do enfoque da mesma. Assim, o presente estudo procura adotar uma perspectiva teórico-abstrata e, ao mesmo tempo, universal, da questão das minorias. 
Como a preocupação consiste em focalizar a problemática per se, isto é, sua dimensão universal, ampla e abstrata, a abordagem é desenvolvida no âmbito da ONU, devido à abrangência global da mesma, em detrimento de âmbitos regionais ou bilaterais. ${ }^{1}$

\section{METODOLOGIAS}

Analogicamente, foi preciso delimitar a dimensão temporal: diante da incontestável atualidade do tema, priorizou-se a análise do tratamento recente da questão, em detrimento de seus numerosos aspectos históricos.

Ao focalizá-los, este estudo busca identificar eventuais aspectos inovadores no âmbito da recente abordagem da ONU, que talvez apontem um redimensionamento da questão de minorias, em nível universal, num sistema internacional já não mais caracterizado pela estrutura bipolar e seus reflexos sobre as estruturas locais, conforme será abordado a situação dos povos indígenas no Estado do Amapá.

\section{DESENVOLVIMENTO DA PESQUISA}

\subsection{IGUALDADE FORMAL X IGUALDADE MATERIAL}

Em seu sentido formal, a igualdade entre todos constitui uma ficção jurídica, um pressuposto ou ponto de partida abstrato cuja afirmação não leva em conta as diferenças de fato existentes entre os seres humanos ${ }^{2}$ : de gênero; etnia; idade; orientação sexual e condição social.

\footnotetext{
${ }^{1}$ Não obstante o fato de que, nas esferas regionais e bilaterais, o tratamento da questão encontra-se, muitas vezes, num estado mais avançado - o que é o caso principalmente em relação a mecanismos e instrumentos europeus (cf., por exemplo, a abordagem no âmbito da Organização sobre Segurança e Cooperação, analisada em BARTSCH, op. cit., pp. 181-254, ou, ainda, mecanismos e instrumentos no contexto do Council of Europe Framework Convention for the Protection of National Minorities). Acordos bilaterais versando sobre proteção de minorias, por exemplo, já definem a(s) minoria(s) que têm corno objeto, dispensando, assim, a complicada tarefa de chegar a definições abstratas ou universais dos beneficiários de direitos, conferidos por um instrumento de abrangência global.

${ }^{2}$ No dizer de Anacleto de Oliveira Faria: "Assim, pois, o significado primeiro da tese de que os homens 'nascem livres e iguais em direitos' implicava na abolição de privilégios, na absoluta nivelação de todos perante a lei; como consequência, ao invés do 'nobre' do 'senhor' do 'vassalo' ou do 'burguês', surgia o vitorioso cidadão [...] a lei reconhece aos cidadãos tratamento igualitário de acordo com as normas gerais e abstratas. A diversidade de sexo, de raça, de língua, de religião, de opinião pública, de condição pessoal ou social não pode constituir razão de tratamento jurídico diverso pelo Estado" (FARIA, 1973. p.49).
} 
A pertença a um estamento superior fazia com que seus membros fossem destinatários de verdadeiras leis particulares, dai o fato de serem titulares de privilégios mais do que propriamente de direitos ${ }^{3}$.

A partir das declarações de direitos do século XVIII, a diversidade de nascimento deixou de poder ser utilizada como justificativa para conceber o outro como alguém desprovido de ou menos direitos.

Neste contexto, o principio da isonomia, ou igualdade em sua vertente formal, representou uma conquista do Estado Liberal, tendo servido de fundamento para se exigir a igual consideração de todos perante uma mesma regra e, consequentemente, a eliminação de qualquer tipo de tratamento discriminatório arbitrário pela lei.

Para a realização deste objetivo, o Estado deveria adotar em essência uma postura abstencionista, de não intervir na esfera da liberdade individual criando privilégios injustificados.

Contudo, a afirmação da igualdade como mero ponto de partida abstrato não foi suficiente para transpor as desigualdades reais entre os seres humanos, que vinham se aprofundando com as precárias condições de trabalho instituídas pós-Revolução Industrial e que só se agravaram no primeiro pós-guerra, com a situação de crise e miséria que dominou a Europa neste período.

A visão de igualdade defendida por Dworkin assenta-se em dois princípios liberais do Individualismo Ético: o princípio da igual importância ou igual valor e o princípio da responsabilidade especial. ${ }^{4}$

Segundo o princípio da igual importância ou do igual valor, é intrínseca, objetiva e igualmente importante que todos os seres humanos tenham vidas bem sucedidas; $́$ É importante, uma vez que qualquer vida humana tenha se iniciado que ela prospere e não fracasse e , acima de tudo, que ela não seja desperdiçada. Isto não significa que todos os seres humanos sejam igualmente bons, igualmente merecedores de apreço e admiração ou igualmente bem sucedidos. A igualdade em questão não se prende a nenhuma característica pessoal, apenas insiste objetivamente que nenhuma vida humana seja desperdiçada.

\footnotetext{
${ }^{3}$ As consequências da Revolução Industrial e das novas formas de exploração econômica do trabalho que dela resultaram, bem como, os efeitos da I Grande Guerra Mundial acabaram contribuindo para a superação da concepção meramente formal de igualdade, própria do liberalismo, em direção aos ideais do Estado Social. Para uma análise dessa transição (BONAVIDES, 1996, p. 59).

${ }^{4}$ Cf. DWORKIN, Ronald. Sovereign Virtue '.. , pp. 05-07. Ver também do mesmo autor: "Do Liberty and Equality Conflict?" in: BARKER, Paul (Editor). Living as Equals. New York: Oxford University Press, 1996, pp. $42-44$.
} 
Dworkin sustenta que a maioria das pessoas já aceita este princípio:

\begin{abstract}
"Você pensa que é importante o que você faz com sua vida, não apenas porque quer fazer algo dela, mas porque você deve querer fazer algo dela. Você pensa que, se por alguma razão, deixasse de se importar com os rumos de sua vida, estaria cometendo um erro. Se é assim, você acredita que é objetivamente importante como você vive. Há alguma coisa diferente em você que poderia tomar isto. verdade para sua vida.. mas não ·para .a vida. das outras pessoas? Você pode jogar com uma resposta positiva. Sim; porque eu sou um dos escolhidos de Deus. Ou porque me foi dado um grande talento que não pode ser desperdiçado. Não há nada logicamente errado com estas respostas, nada que demonstre serem irracionais. Mas não é o que você pensa, pelo menos ao refletir. Sabemos que somos diferentes uns dos outros. Temos diferentes histórias, tradições e talentos, e cada um de nós deve viver da maneira que for mais apropriada a quem e ao que se é. Mas essas qualidades pessoais são parte do desafio de se viver bem, não razões pelas quais encaramos o desafio. Não pensamos que não importaria como viveríamos se não fossemos judeus ou musculosos ou franceses ou poetas. Pensamos que é importante como vivemos pela razão absolutamente concreta de termos uma vida para levar, porque somos humanos e mortais". 5
\end{abstract}

É importante destacar a validade universal do princípio da igual importância e da argumentação reproduzida. Sem invocar razões metafisicas, Dworkin é bastante convincente a respeito do valor atribuído pelas pessoas, pelo menos teoricamente, não somente à sua própria vida, mas a cada vida humana.

Tal princípio pode fundamentar não apenas o modelo de igualdade proposto por Dworkin, mas também contribuir para o diálogo transcultural no Direito Internacional dos Direitos Humanos, à medida que oferece interpretação de forte apelo universal para as premissas de reciprocidade e de igual dignidade: não importa à qual tradição cultural se pertença, todos, a partir de sua própria existência, querem que toda e cada vida humana "floresça" e não se desperdice.

O segundo princípio do individualismo ético é o princípio da responsabilidade especial declara que a ligação entre cada indivíduo e sua própria vida, apesar de assumir o igual valor de todas as vidas, é especial. Dworkin argumenta: "Alguém que trate sua própria vida como não tendo um lugar diferente em seus próprios planos e sem maior apelo à sua própria atenção do que a vida de qualquer estranho não seria um santo, mas um marciano. ${ }^{6}$

O princípio da responsabilidade especial também não é metafísico. Trata-se, no dizer de Dworkin, de princípio relacional: insiste que as escolhas feitas por cada um a respeito da vida que pretende viver são de responsabilidade pessoal. O princípio não endossa escolha de valor ético. Ele apenas afirma que viver é "tarefa" que pode ser bem ou mal executada. Há aqui um desafio intelectual: a escolha do melhor modus vivendi, que é pessoal mais do que

\footnotetext{
5 DWORKIN, Ronald. "Do Liberty and Equality Conflict?, p ..43. ${ }^{6}$ Idem, p. 43 (trad. do mestrando - destaques apostos).
} 
político no sentido de que a concepção de vida do indivíduo não lhe foi imposta. Viver bem, de acordo como princípio da responsabilidade especial, requer tanto compromisso pessoal, como meio social no qual tal compromisso seja encorajado e respeitado, para além do individualismo.

Se para uma vida digna exige-se compromisso moral da comunidade personificada, não se exige menor compromisso de seus membros individualmente.

É sobre os dois princípios do individualismo ético, atuando em concerto, que Dworkin elabora sua concepção de equal concern. Ainda que o primeiro pareça mais igualitário no conteúdo do que o segundo; e o segundo pareça mais relacionado ao ideal de liberdade, Dworkin enfatiza que não há conflito entre os dois princípios:

o primeiro - do igual valor - não contradiz o segundo, porque não me exige que aceite responsabilidade pelo sucesso de qualquer outra vida além da minha; ele apenas exige meu reconhecimento que de um ponto de vista impessoal - a visão apropriada ao governo de uma comunidade política, por exemplo - meu próprio destino não deve importar mais do que o de qualquer outra pessoa. ${ }^{7}$

Esboça-se a interpretação oferecida por Dworkin para a noção de interdependência entre os ideais políticos de liberdade, igualdade e comunidade, adotada pela concepção contemporânea de direitos humanos.

A interdependência entre esses ideais é trazida para a realidade internacional, de maneira substancial, para a superação do subdesenvolvimento, pela obra de Amartya Sen:

De fato, a condição de agente dos indivíduos é, em última análise, central para lidar com essas privações. Por outro lado, a condição de agente de cada um é inescapavelmente restrita pelas oportunidades sociais, políticas e econômicas de que dispomos. Existe uma complementaridade entre a condição de agente individual e as disposições sociais: é importante o reconhecimento simultâneo da centralidade da liberdade individual e da força das influências sociais sobre o grau e o alcance da liberdade individual. Para combater os problemas que enfrentamos temos de considerar a liberdade

(...)

A liberdade individual é essencialmente um produto social, e existe uma relação de mão dupla entre (1) as disposições sociais que visam expandir as liberdades individuais e (2) o uso de liberdades individuais não só para melhorar a vida de cada um mas também para tornar as disposições sociais mais apropriadas e eficazes. ${ }^{8}$

Na perspectiva de Sen, de "desenvolvimento como liberdade", os indivíduos devem estar ativamente envolvidos na formação de seus destinos, desde que tenham as devidas oportunidades, e não somente como beneficiários passivos dos resultados de planos engenhosos de desenvolvimento. Cabe ao Estado e à sociedade assegurar as condições de

\footnotetext{
${ }^{7}$ Idem, p. 44.

${ }^{8}$ SEN, Amartya. Desenvolvimento .... pp. 10,46 (destaques apostos).
} 
existência das oportunidades para a atuação individual. Seu papel do Estado e da sociedade é "de sustentação, não de entrega sob encomenda". 9

Tal como Dworkin, Sen também reconhece o princípio da "especial responsabilidade" traduzido na exigência de ativo envolvimento dos indivíduos na conformação de seus destinos. Mas o autor indiano, ante a realidade do subdesenvolvimento, acentua a importância da correlação entre o compromisso social através do esforço coletivo e a extensão das "capacidades individuais". Estas dependem crucialmente de arranjos econômicos, políticos e social. A perspectiva de Sen surge diretamente como resposta aos desafios concretos do desenvolvimento que, para o autor, consiste na expansão das liberdades humanas e " ... na eliminação de privações de liberdade que limitam as escolhas e as oportunidades das pessoas de exercer ponderadamente sua condição de agente. A eliminação de privações de liberdades substanciais, (...), é constitutiva do desenvolvimento". ${ }^{10}$

Constata-se que os dois autores tratam, de perspectivas distintas, do tema da inter-relação entre liberdade, igualdade e comunidade: Dworkin, na elaboração e defesa da teoria política do liberalismo igualitário; Sen, a partir de seu papel no desenvolvimento econômico e social. Em ambos os projetos, os autores propõem concepções de igualdade.

A contraposição entre a concepção de Sen e a de Dworkin será útil para o melhor entendimento do alcance e limites da teoria do liberalismo igualitário no Direito Internacional dos Direitos Humanos.

Passa-se, então, a verificar o papel dos dois princípios do Individualismo Ético proposto por Dworkin na formação de sua concepção de igualdade liberal.

No plano do direito internacional dos direitos humanos, essas ideias estão na base do chamado processo de especificação dos sujeitos de direitos, segundo o qual, além de direitos gerais universais, extensíveis a todos, há necessidade de se reconhecer direitos específicos a determinados grupos vulneráveis dentro da sociedade. Isso com o objetivo de se atingir a igualdade real, ou pelo menos, reduzir as desigualdade de fato existente.

É neste contexto que surge o direito à diferença:

[...] na esfera internacional, se uma primeira vertente dos instrumentos internacionais nasce com a vocação de proporcionar uma proteção geral, genérica e abstrata, refletindo o próprio temor da diferença, percebe-se, posteriormente, a necessidade de conferir a determinados grupos uma proteção especial e particularizada, em face de sua própria vulnerabilidade. Isso significa que a diferença ao mais seria para a aniquilação de direitos, mas, ao revés, para sua promoção. (PIOVESAN, 2005, p.43).

\footnotetext{
${ }^{9}$ Idem, p. 71.

${ }^{10}$ Idem, p. 10.
} 


\section{O PRINCÍPIO DA IGUALDADE MATERIAL E A PROTEÇÃO AS MINORIAS}

Para José Reinaldo de Lima Lopes, o conceito de minoria está ligado a vitimização de um determinado grupo por um tipo específico de lesão ou dano, submetendo-o a um papel subalterno, fruto de alguma forma de exploração, violência, crueldade, expropriação. Note-se que não se trata de um conceito numérico, pois pode acontecer de uma minoria numérica controlar uma maioria, colocando-a em posição de subordinação em relação a uma elite, como ocorre em uma oligarquia. Neste caso, a maioria torna-se vítima de uma ação ou situação em que lhe são negados recursos de poder, tornando-a mais fraca e vulnerável $^{11}$.

A vulnerabilidade é uma característica relevante para a formação dos grupos minoritários merecedores de uma proteção diferenciada e ela se agrava quando a vitima pertence a um grupo que por tradição, costume ou preconceito, tem mais dificuldade de acesso a direitos ou recursos de poder existentes na sociedade, tal como as mulheres, os negros, os homossexuais, as minorias religiosas, os imigrantes e os povos indígenas.

As características que servem de base para fundamentar as diferenças de identidade dos grupos minoritários podem ser mutáveis ou imutáveis, naturais ou artificiais, visíveis ou invisíveis.

As características imutáveis levariam a formar grupos naturais, e as diferenças invisíveis permitiriam que elas fossem reservadas para a esfera da vida privada, formando os grupos artificiais. Ser negro ou branco, ser homem ou ser mulher seriam características imutáveis e visíveis. Ser espírita ou católico seriam características invisíveis e mutáveis pela conversão.

Nem sempre as características naturais visíveis de um grupo são suficientes para constituí-lo enquanto minoria. Assim, observa-se o papel da tradição, do costume e do preconceito. A dominação de um grupo sobre outro, seja fundamentada em características mutáveis ou imutáveis, visíveis ou invisíveis, é que determina sua situação de vulnerabilidade. Tanto é que, no caso dos negros, por exemplo, hoje se reconhece que não existe, do ponto de vista biológico, uma diferenciação de raças na espécie humana, que é uma só. Contudo isso não significa que não exista a prática do racismo fundada em uma construção histórico - cultural. Assim para desconstruí-la, devem-se criar mecanismo para combater a utilização das diferenças ou particularidades de um grupo ainda que artificiais e

\footnotetext{
${ }^{11}$ Lopes, J. (2000, p.7).
} 
sem base científica, como no caso dos negros como justificativas para privá-lo de direitos, bens ou reconhecimento do seu direito de participação na sociedade em igualdade de condições com os demais membros desta.

O problema é que ainda há uma polêmica em torno da legitimidade das reinvindicações dos grupos minoritários. Há minorias étnicas e culturais cujas demandas limitam-se ao reconhecimento de espaços privados, como associações voluntárias.

Outros se transformam em movimentos não integrados nacionalmente, como os grupos separatistas, cujo caráter democrático é alvo de críticas.

Há ainda minorias integradas nacionalmente, mas que procuram essencialmente o reconhecimento de sua identidade com base na ideia de que as regras universais não são suficientes para garantir o seu direito a diferença.

Outros ainda buscam o estabelecimento de regras próprias para sua vida familiar, podendo demandar escolas próprias para que as crianças pertencentes a esses grupos possam ser socializadas de acordo com valores diferentes.

Nesse caso, justifica-se romper com as leis universais e de integração, ou estaríamos diante de praticas segregacionistas?

[...] As minorias podem dizer que tratamentos tidos por universais e equânimes resultam de fato em privação de recursos ou de respeito para quem pertencer a determinado grupo. Pode acontecer que a regra que impõe um tratamento universal de fato valoriza uma forma de vida e desvaloriza outra e que ao ser desvalorizado sua forma de vida, autonomamente eleita, constitutiva da liberdade daqueles que pertencem ao grupo minoritário, esta sendo negada uma parcela inestimável sem preço de sua condição humana. (LAFER, 2004, p.53).

Ao valorizar diferentemente, sem justificativa plausível, certas distinções, a ordem politica e jurídica estaria violando o principio da igual dignidade humana, forma democrática de dignidade. O sistema jurídico e politico pode esta apoiando ou permitindo que modos sociais de desrespeito as minorias sobreviviam ou se multipliquem: aceitando o principio da segregação ou da hierarquização social. Ora, o direito democrático tem por função eliminar os incentivos jurídicos e institucionais a estas discriminações e hierarquizações [...] As minorias reivindicam a dignidade moderna e potencialmente democrática de verem respeitadas as suas formas de vida independentemente do juízo que se faça dela, desde que esta forma de vida não imponha violência a ninguém.( LAFER, 2004, p.53).

Veremos que a legitimidade das reivindicações dos grupos minoritários do ponto de vista filosófico e jurídico em sociedades democráticas depende das duas vertentes 
em que o principio da igualdade material se subdivide. Vejamos, então, em que consiste cada uma delas e como elas são relacionadas.

\section{AS DUAS VERTENTES DO PRINCIPIO DA IGUALDADE MATERIAL: REDISTRIBUIÇÃO E RECONHECIMENTO}

A busca pela igualdade material pode estar orientada por dois critérios. Quando embasada pelo critério socioeconômico, corresponde ao ideal de justiça distributiva e requer, para sua realização, a adoção de medidas concretas de enfrentamento da marginalização e da desigualdade real.

O conceito de justiça distributiva está relacionado ao princípio da solidariedade ${ }^{12}$, que diz respeito a relação que se estabelece entre as partes de um todo: entre si e perante o próprio todo. Segundo tal princípio, a relação de todos os cidadãos entre si, ou da sociedade através de um conjunto de cidadãos com qualquer um deles em particular para fugir a tendência à atomização, impõe deveres positivos da colaboração, levando-se em conta as diferenças de condição social entre os membros da sociedade ${ }^{13}$.

Trata-se da aplicação de um critério de justiça que busca, na distribuição de bens e serviços pelos poderes públicos, a compensação entre os que têm e os que não têm.

Uma das espécies de justiça em sentido estrito e do que é justo na acepção que lhe corresponde, é a que se manifesta na distribuição de funções elevadas de governo, ou de dinheiro, ou das outras coisas que devem ser divididas entre os cidadãos que compartilham dos benefícios outorgados pela constituição da cidade, pois em tais coisas uma pessoa pode ter uma participação desigual ou igual á de outra pessoa; a outra espécie é a que desempenha uma função corretiva nas relações entre as pessoas ${ }^{14}$.

O equilíbrio próprio da justiça proporcional implica o reconhecimento da noção de que, em relação aos grupos vulneráveis, a justiça comutativa, própria da relação entre iguais quando aplicada, produz o efeito perverso de agravar a desigualdade.

\footnotetext{
${ }^{12}$ A solidariedade deve ser compreendida como um dever jurídico, fundamento dos direitos sociais: "Com base no princípio da solidariedade, passaram a ser reconhecidos como direitos humanos os chamados direitos sociais que se realizam pelas políticas públicas, destinadas a garantir amparo e proteção social aos mais fracos e mais pobres, ou seja, aqueles que não dispõem de recursos próprios para viver dignamente" (COMPARATO, 2003. p. 64).

${ }^{13}$ Comparato (2003. p. 52).

${ }^{14}$ Aristóteles (2000,. Livro V. 1131,a.)
} 
Honneth tira o foco da motivação moral dos conflitos sociais e o coloca na explicitação das vulnerabilidades associadas ao rompimento das relações de reconhecimento. Com isso, ele enfatiza também a importância de atentar para as vulnerabilidades dos indivíduos, conceito que até então tinha sido usado por Honneth apenas esporadicamente para designar de modo mais amplo a dependência que todos possuem de relações de reconhecimento.

A normatividade da teoria de Honneth não é extraída das lutas políticodemocráticas, mas sim das carências vinculadas a relações intersubjetivas de reconhecimento que têm de ser sanadas para que os indivíduos possam escolher quais caminhos trilhar. Ainda que explicitem a importância da intersubjetividade e enfatizem, contra os liberais, que a própria formação da individualidade depende diretamente de relações sociais de reconhecimento, essa intersubjetividade é pensada a partir de um "âmbito privado" e não, por exemplo, a partir de procedimentos democráticos de justificação.

Parece possível afirmar que as próprias lutas por reconhecimento possuem um caráter pré-político. Elas não decorrem da divergência pré-política entre interesses privados distintos, como em muitas teorias liberais da democracia, mas estão diretamente vinculadas à necessidade pré-política dos indivíduos de estarem amparados por relações recíprocas de reconhecimento em três diferentes esferas. A garantia da autonomia pessoal e da própria justiça são pensadas a partir das condições sociais que permitem ao indivíduo conduzir a vida que determinou como boa.

Com isso, a autonomia pública, atrelada a processos deliberativos de formação política da opinião e da vontade, possui um papel secundário. Consequência que acaba por explicitar alguns dos pontos em que a posição de Honneth se distingue daquela sustentada pelos defensores de um modelo deliberativo de democracia, como Habermas, para quem autonomia pública e privada são cooriginárias.

Assim, se uma determinada lei limita-se a garantir um direito sem oferecer condições concretas, para que grupos despidos de poder econômico ou politico possam dele usufruir, tal situação, via de regra, acaba contribuindo para que apenas aqueles que já estão em uma situação de vantagem possam de fato exercer tal direito ${ }^{15}$.

\footnotetext{
${ }^{15}$ Para José Reinaldo de Lima Lopes, “a justiça comutativa - retributiva tornou-se uma questão de direito e a justiça distributiva tornou-se política [...] No caso do direito constitucional, particularmente nos casos de disputa judicial sobre a constitucionalidade da lei ou atos da administração, política e direito voltam a juntar-se [...] Nas questões de justiça propriamente dita há outros problemas . Em primeiro lugar o da legitimidade política. A justiça distributiva diz respeito a regras de apropriação individual de recursos comuns [...]. Tais regras, pela sua
} 
Por essa razão, a fruição de direitos fundamentais pelas camadas desfavorecidas da população exigem a implementação de medidas que tenham como alvo prioritário, justamente, os grupos vulneráveis, conferindo-lhes condições concretas de acesso aos bens e recursos socialmente produzidos. Neste caso, a justiça distributiva é fundamento das políticas sociais necessárias para a realização do Estado Social de Direito ${ }^{16}$.

Um exemplo atual de aplicação prática do critério da justiça distributiva consistente na submissão do sistema tributário ao princípio da capacidade contributiva de cada um, atribuindo-se as prestações publicas de bens e serviços aos cidadãos, de acordo com suas necessidades. A distribuição desses bens deve ser feita pelo Estado, responsável pela organização dos sistemas públicos que dão concretude aos direitos fundamentais, levando-se em conta as diferenças naturais e culturais entre os grupos de seres humanos, de tal forma que ela se dê de modo proporcional.

Mas a igualdade material também pode assumir outra vertente, correspondente ao ideal de justiça em quanto ao reconhecimento de identidades ou status, como veremos em seguida. Dessa forma, estamos falando da igualdade orientada pelos critérios de gênero, orientação sexual, raça e etnia. A concretização deste princípio requer a adoção de medidas de enfrentamentos dos preconceitos e padrões discriminatórios arraigados na sociedade. Tal orientação está na base das teorias formuladas por filósofos políticos da atualidade que tem como foco prioritário a busca pelo reconhecimento das distintas perspectivas das minorias.

O problema é que os defensores de redistribuição nem sempre se alinham aqueles que privilegiam o reconhecimento. Tomando-se o exemplo do movimento feminista, há aqueles que defendem a redistribuição como remédio para enfrentar a dominação

generalidade, não podem ser definidas para um caso só, por isso observa-se o sentimento de injustiça nas decisões judiciais, rompendo com a regra formal da justiça em que todos pertençam a mesma classe social sejam tratados de maneira igualitária [...] As decisões que pretendem fazer justiça distributiva ou sob o pretexto de fazer justiça comutativa, estão de fato envolvidas em questões distributivas, gerando tratamento desigual e retirando de uma certa classe um determinado indivíduo [...] Institucionalmente o Judiciário está pouco aparelhado para fazer justiça distributiva à medida que foi construído para atender e supervisionar conflitos individuais e, sobretudo, bilaterais, em que há um jogo de soma zero. (LOPES, 1994, p. 25-26; 29-30).

16 Na sua origem, o Estado de Direito é um conceito típico do liberalismo, cujas características básicas são: submissão do poder estatal ao império da lei (princípio da legalidade), separação dos poderes como garantia das liberdades e controles de abusos e, por fim, o reconhecimento de garantias e direitos individuais incorporados às Constituições. Ocorre que, o individualismo e o abstencionismo do Estado Liberal geraram crises sociais e econômicas que culminaram em sua substituição pelo Estado Social de Direito. Este novo modelo busca compatibilizar o sistema econômico capitalista com a melhoria das condições sociais por meio da atuação estatal. O Estado Social, sem abandonar as características essenciais do Estado de Direito, as supera ao incorporar como um de seus objetivos essenciais a transformação do status quo, por meio da busca pela redução das desigualdades sociais e da realização da justiça social. 
masculina e outros que focam na necessidade de garantir o reconhecimento de questões de gênero entendidas como um fator de identidade cultural.

A pauta de reivindicações dos defensores da redistribuição nem sempre se alinham aqueles que privilegiam o reconhecimento por vezes chega a se chocar. Isso por que em algumas situações aqueles que advogam a necessidade de politica de redistribuição consideram as exigências de reconhecimentos das diferenças como um desvio, um obstáculo para alcance da justiça social e vice-versa.

Defenderemos a ideia de que tal oposição é falsa e merece ser combatida, pois nenhuma dessas concepções por si só é suficiente para se atingir um ideal amplo de justiça. Utilizaremos, como fundamento, a tese defendida por Nancy Fraser (2007), que sustenta a importância de se elaborar um conceito de justiça que abranja tanto reinvindicações de redistribuição como de reconhecimento, conciliando os aspectos emancipatórios das duas perspectivas. Mas, afinal, será que é possível combinar essas duas visões em um conceito amplo de justiça?

Para Fraser (2007), a tarefa de combinar esses dois modelos só terá êxito se a identidade cultural especifica de um grupo deixar de ser utilizada como padrão de seu reconhecimento em oposição a cultura dominante que a deprecia. Isso porque, ao tratar aspectos culturais de um grupo como profundamente definidos e separados, o modelo da identidade tenderia a promover o separatismo e o fechamento dos grupos em si mesmos, em vez de incentivar uma maior interação entre eles. A alternativa seria, na visão de Fraser, tratar o reconhecimento como uma questão de status social, pois o que exige reconhecimento não é a identidade especifica de um grupo, mas a condição dos membros do grupo como parceiros integrais na interação social.

A criação de um modelo de igualdade de status esta baseada na ideia de que o não reconhecimento deve ser combatido sempre que os padrões institucionalizados de valores cultural forem utilizadas para transformar alguns autores em sujeitos inferiores, excluídos, invisíveis, ou seja, como menos de parceiros integrais na interação social.

Neste contexto o não reconhecimento ocorre quando determinadas praticas, normas ou instituições negam a determinados grupos a oportunidade de participar como iguais em relação aos demais nos mecanismos de interação social existentes. É o que se passa, por exemplo, quando se criam normas matrimoniais que não alcançam a união entre pessoas do mesmo sexo. 
O grande objetivo no modelo de status é realizar a justiça de modo concreto por meio da superação dos mecanismos de subordinação e exclusão institucionalizados. De acordo com este modelo, a justiça não depende da mera redistribuição de recursos econômicos ou de direitos. É preciso atacar, também, as injustiças que decorrem dos padrões institucionalizados de valorização cultural, sem, contudo, utilizara identidade de grupo como fator de referência.

Outro exemplo que serve para ilustrar a exigência de reconhecimento calcada na paridade de participação refere-se a polemica francesa quanto a utilização dos véus pelas meninas mulçumanas em escolas públicas. Assim, estamos diante de um tratamento injusto a uma minoria religiosa? Para Fraser (2007), o reconhecimento do direito do uso do véu depende da comprovação de dois requisitos. Primeiro, de que a sua proibição constitui a imposição de uma prática cultural majoritária injusto, que nega paridade educacional às meninas mulçumanas. Depende, também, da demonstração de que o uso do véu não constitui uma prática que contribui para o reforço da subordinação feminina em comunidades mulçumanas ou na sociedade em geral.

No primeiro caso, é fácil comprovar que não há nenhuma proibição analógica que impede o uso de cruzes cristãs nas escolas públicas. Assim, a proibição do uso do véu constitui uma prática que viola a igualdade de condições de participação no sistema educacional das cidades mulçumanas.

O cumprimento do segundo requisito, porém, é muito mais controvertido. Isso porque alguns franceses acreditam que a utilização do véu é uma evidência da subordinação feminina e como tal, deve ser suprida da esfera pública de outro lado, para alguns defensores do multiculturalismo, vedar o reconhecimento do uso do véu seria desprestigiar uma prática altamente valorizada nas comunidades mulçumanas francesas, de forma que o Estado estaria deixando de permitir a expressão de um símbolo da identidade mulçumana, ainda que em transição.

$\mathrm{Na}$ visão de Fraser (2007), neste caso, diferentemente do que ocorre com o clássico exemplo da prática de mutilação genital feminina que nega a paridade no prazer sexual e na saúde das mulheres e meninas, é possível justificar a reivindicação do reconhecimento desta diferença cultural em termos de paridades de participação. 
Uma das grandes vantagens do modelo de status consiste na consideração de que, se muitas injustiças são consequência do não reconhecimento, há casos em que preciso atacar, também, a própria estrutura econômica para se alcançar a paridade de participação ${ }^{17}$. Assim, é preciso combinar distribuição e reconhecimento, reconhecendo ambas como dimensões do conceito de justiça:

[...] a justiça requer arranjos sociais que permitam a todos os membros da sociedade interagir uns aos outros como parceiros. Para que a paridade de participação seja possível, eu afirmo que, pelo menos, duas condições devem ser satisfeitas. Primeiro, a distribuição de recursos materiais deve dar-se de modo que assegure a independência e voz dos participantes. Essa eu denomino a condição objetiva da paridade participativa. Ela exclui formas e níveis de desigualdade material e dependência econômica que impedem a paridade de participação [...] (FRASER, 2004, p.130).

Ao contrário, a segunda condição requer que os padrões institucionalizados de valoração cultural expressem igual respeito a todos os participantes e assegurem igual oportunidade para alcançar estima social. Essa denomina-se a condição intersubjetiva de paridade participativa. Ela exclui normas institucionalizadas que sistematicamente depreciam algumas categorias de pessoas e as características associadas a elas.

Um dos maiores defensores do multiculturalismo, Boaventura de Souza Santos (2010), assim como Nancy Fraser (2007), considera a necessidade de se conjugar as duas dimensões da justiça para combater fenômenos de hierarquização como o racismo e o sexismo ${ }^{18}$. Faz-se uma distinção entre os conceitos de desigualdade atrela a fatores socioeconômicos e exclusão, fruto de manifestações socioculturais, reconhecendo, no entanto, que ambos os fatores podem atuar simultaneamente, devendo-se, portanto, recorrer a remédios de justiça distributiva e de reconhecimento das diferenças para superá-las.

No caso do racismo, o principio da exclusão assenta na hierarquia das raças e a integração desigual ocorre, primeiro, através da exploração colonial como a escravatura e o trabalho forçado, e, depois através da imigração. No caso do sexismo, o principio da exclusão assenta a distinção entre o espaço privado e o principio da integração desigual, no papel da mulher na reprodução da força de trabalho no seio da família e, mais tarde, tal como o racismo, pela integração em formas desvalorizadas de sua força de trabalho.

\footnotetext{
${ }^{17}$ Paridade significa a condição de ser um par, de estar em igual condição com os outros, de estar partindo do mesmo lugar.

${ }^{18}$ Sousa Santos (2010, p. 281).
} 
Trata-se de um processo histórico através do qual uma cultura, por via de um discurso de verdade, cria o interdito e o rejeita. Estabelece um limite para além do qual só há transgressão , um lugar que atira para outro lugar, a hetorotopia, todos os grupos sociais que são atingidos pelo interdito social, sejam eles a delinquência, a orientação sexual, a loucura ou crime. Através das ciências humanas, transformadas em disciplinas, cria-se um enorme dispositivo de normalização que, como tal, é simultaneamente qualificador e desqualificador. A desqualificação como inferior, louco, criminoso ou pervertido consolida a exclusão e é a perigosidade pessoal que justifica a exclusão. A exclusão da normalidade é traduzida em regras jurídicas que vinculam, elas próprias, a exclusão. Na base da exclusão está uma pertença, um modo específico de dominar a dissidência. Assenta num discurso de fronteiras e limites que justificam grandes fraturas, grandes rejeições e segregações. Sendo culturais e civilizacionais, tais fraturas têm também consequências sociais e econômicas, ainda que não se definam primordialmente por elas.

Sousa Santos (2010) cita, como um exemplo de exclusão em seu grau mais extremo, o extermínio dos índios na conquista da América, dos armênios no final do Império otomano, dos judeus e ciganos no nazismo.

Atualmente, as exclusões se aprofundam pelas novas praticas de racismo e xenofobia presentes na Europa. Já o grau mais elevado da desigualdade é a escravidão.

Exclusão e desigualdade se cruzam frequentemente no sistema mundial: a dominação socioeconômica do Imperialismo e mais recentemente a globalização neoliberal convivem com os números choques culturais entre o Ocidente e o Oriente. Um exemplo atual de aprofundamentos das desigualdades entre o eixo Norte-Sul é o chamado imperialismo biológico, que protege a propriedade intelectual, o conhecimento produzido pelas empresas multinacionais, mas não reconhece os conhecimentos tradicionais dos povos indígenas a partir do qual o conhecimento dito científico é gerado.

Da mesma forma, quando se trata do acesso aos remédios utilizados contra o HIV-AIDS (Vírus da Imunodeficiência Humana/ Síndrome da Imunodeficiência Adquirida), os acordos internacionais de comércio costuma favorecer o monopólio das empresas farmacêuticas transnacionais, consolidam a proteção das patentes em detrimento dos países produtores de genéricos, como é o caso do Brasil, que ficam proibidos de exportar tais medicamentos, ou podendo fazê-lo apenas sem situação de emergência do domínio da saúde pública. 
A tese de Sousa Santos (2010) é a de que regulação social da modernidade capitalista é caracterizada por processos que geram cada vez mais desigualdade e exclusão. No entanto, o sistema permite a incorporação de mecanismo para fugir da desigualdade e das exclusões extremas ou pelo menos mantê-las em níveis controlados.

Vale ressaltar que o que se chama de gestão controlada das desigualdades e da exclusão não constitui uma mera concessão do Estado capitalista, mas, sim, uma conquista das lutas sociais que impuseram políticas redistributivas e formas menos agressivas de exclusão.

O problema é que a gestão da desigualdade e da exclusão no sistema capitalista está calcada fundamentalmente no universalismo, que podem assumir duas formas contraditórias: o universalismo antidiferencialista que é baseada na negação das diferenças culturais, absolutizando uma delas e excluindo as demais e o universalismo diferencialista que, com base no relativismo, absolutiza as diferenças, negando a possibilidade de comparálas por meio de um diálogo intercultural.

O universalismo antidiferencialista, esclarece Boaventura de Souza Santos (2010), operou por meio das políticas sociais e econômicas do Estado - providência e da social - democracia nos países centrais e por meio das políticas desenvolvimentistas nos países periféricos. Os direitos econômicos universais e as politicas compensatórias hoje de que são exemplos o fome-zero, o bolsa-escola e a assistência social correspondem a criação de mecanismos para, quando muito, manter a desigualdade em níveis toleráveis.

Ocorre que este modelo de produção e gestão da desigualdade e da exclusão estaria atualmente em crise. Primeiro, porque as politicas fiscais e monetárias estão hoje voltadas para o controle da inflação, do déficit público, para a estabilidade da balança de pagamentos, prejudicando a expansão das prestações materiais fornecidas pelo Estado. Segundo, pelo processo de desnacionalização do Estado, em função da globalização, que comprometeria a sua capacidade de regulação da economia política nacional e das políticas de bem estar social. O velho paradigma do Estado Keynesiano centralizado, promotor do pleno emprego e voltado para as políticas sociais de redistribuição, apesar de nunca terem sido propriamente implementado na sua plenitude em países periféricos como o Brasil, está em crise mesmo nessas regiões. Acrescente-se, ainda, a queda dos regimes socialistas que outrora serviam de modelo de combate à desigualdade.

No que se refere às políticas de reconhecimento das diferenças, Boaventura critica o fato de estas estarem voltadas, também, quando muito, para uma gestão controlada da exclusão. Tanto é assim que a inclusão das mulheres no mercado de trabalho e a ampliação de 
seus direitos de cidadania não foram suficientes para livrá-las da desigualdade, pois seus salários continuam inferiores aos dos homens. No entanto, muitas políticas de seguridade social, ao pressuporem a família heterossexuais, bígamos ou sem base no casamento tradicional, gerando portanto, mais exclusão. Isso mostra como, no sistema de desigualdade, o fator classe continua tendo um papel preponderante, mas, outros fatores vêm contribuindo para agravar o seu potencial discriminador, tais como raça, etnia e gênero.

A proposta de Boaventura de Sousa Santos (2010) é criar um metadireito intercultural que deverá conduzir a articulação pós-colonial e multicultural, negando a homogeneização cultural e a ideia de unidade cultural nacional do Estado, sem, contudo, cair na fragmentação pura e simples. É preciso equilibrar direito à igualdade e reconhecimento da diferença. Para tanto, é preciso conciliar os mecanismos tradicionais de democracia representativa que privilegiam a vontade da maioria, com mecanismo que tenham como foco correções de suas distorções, gerando desrespeito aos direitos das minorias e aprofundamento das desigualdades existentes.

\section{O PAPEL DO ESTADO NO COMBATE À DISCRIMINAÇÃO E NA REALIZAÇÃO DA IGUALDADE MATERIAL}

Para realização do principio da igualdade material, o Estado passa a ter obrigações concretas e positivas. Será necessário estabelecer os grupos que merecem um tratamento diferenciado e as ações a serem implementadas para permitir o acesso desses grupos aos bens socialmente produzidos, garantir a redução das desigualdades econômicas e que os padrões institucionalizados de valoração cultural deixem de excluir ou respeitar algumas categorias de pessoas.

Trata-se da adoção de medidas de discriminação em sentido positivo ou de diferenciação, que devem ser plenamente justificadas à luz dos objetivos próprios do Estado Social Democrático de Direito, notadamente a promoção da justiça social e do respeito ao direito à diferença e à pluralidade.

Diferentemente, a discriminação em sentido negativo deve ser combatida. Ela significa toda distinção, exclusão, restrição ou preferência que tenha por objetivo ou resultado prejudicar ou anular o exercício, em igualdade de condições, dos direitos humanos e liberdades fundamentais nos campos político, econômico, social, cultural e civil ou em qualquer outro campo. 
Segundo Flávia Piovesan (2005), há duas formas de enfrentar a problemática da discriminação. A primeira delas consiste na adoção de estratégias de caráter repressivo, com o objetivo de punir, proibir e eliminar práticas que configurem discriminação arbitraria. A segunda se materializa por meio da adoção de estratégias de caráter promocional, com o objetivo de promover, fomentar e ampliar a igualdade de fato, por meio da efetiva inclusão social de minorias grupos vulneráveis e da implementação de políticas compensatórias de que são exemplos as ações afirmativas.

A convenção sobre a eliminação de todas as formas de discriminação racial, ratificada pelo Brasil em 1968, constitui um exemplo concreto de um instrumento jurídico, no plano internacional, que estabelece o dever dos Estados signatários de adotarem ações positivas no combate à discriminação e desigualdade raciais ${ }^{19}$. O art. $1^{\text {o }} \S 4^{\circ}$ do referido documento prevê expressamente a possibilidade de adoção das ações afirmativas, entendidas como medidas necessárias e legítimas para aliviar, remediar e transformar o legado de um passado discriminatório contra certos grupos raciais ou étnicos.

Não serão considerados discriminação racial as medidas especiais tomadas como o único objetivo de assegurar o progresso adequado de certos grupos raciais ou étnicos ou de indivíduos os quais necessitam proteção que possa ser necessária para proporcionar a tais grupos ou indivíduos igual gozo ou exercício de direitos humanos e liberdades fundamentais, desde que tais medidas não conduzam, em consequência, a manutenção de diretos separados para diferentes grupos raciais e não prossigam após terem sido alcançados seus objetivos ${ }^{20}$.

Trata-se da consagração explícita, no plano jurídico, do principio da igualdade material como fundamento para a adoção de medidas concretas por meio das quais é possível enfrentar tanto a injustiça social e econômica através do direito à redistribuição, como também a injustiça cultural por meio do direito ao reconhecimento.

Há inúmeras estratégias de promoção da igualdade material. As ações afirmativas são apenas um exemplo de medidas concretas que apresentam caráter redistributivo e/ou de reconhecimentos de direitos de grupos vulneráveis ou socialmente

\footnotetext{
${ }^{19}$ No que diz respeito especificamente à discriminação racial, está comprovado que do ponto de vista científico, não existe um conceito biológico de raça. Trata-se de um conceito histórico-cultural, artificialmente construído para justificar práticas discriminatórias arbitrárias sem embasamento científico, ele deverá ser utilizado para fundamentar política de inclusão social de grupos historicamente marginalizados que tenham como objetivo justamente combater as práticas discriminatórias excludentes. Na síntese de Celso Lafer: "Se o racismo não pode ser justificado por fundamentos biológicos, ele, no entanto, persiste como fenômeno social" (LAFER, 2004, p.58).

${ }^{20}$ Convenção sobre a Eliminação de todas as formas de Discriminação Racial. Op.cit.
} 
desfavorecidos e que tem como objetivo corrigir uma situação de desigualdade historicamente comprovada e/ou integrar comunidades excluídas.

Segundo Joaquim Barbosa Gomes (2000), eles podem ser definidas como: O conjunto de políticas públicas e privadas de caráter compulsório, facultativo ou voluntário, concebidas com vistas ao combate da discriminação racial, de gênero, de origem nacional, tendo por objetivo a concretização do ideal de efetiva igualdade de acesso a bens fundamentais como a educação e o emprego ${ }^{21}$.

Vale ressaltar que a ação afirmativa não é necessariamente sinônimo de política de cotas, as cotas são apenas uma espécie de ação afirmativa, talvez a mais conhecida e mais polêmica entre elas, mas há outros exemplos, dentre os quais podemos destacar: a adoção de incentivos fiscais, a criação de um sistema de sanções promocionais o estabelecimento de um sistema de preferências ou de bônus.

\section{PRINCÍPIO DA IGUALDADE MATERIAL NA CONSTITUIÇÃO FEDERAL DE 1988}

A Constituição Federal de 1988 consagra, simultaneamente, o principio da igualdade formal perante a Lei e o da igualdade material feita pela $\operatorname{Lei}^{22}$. Ela não se contenta com a posição abstencionista característica do Estado Liberal, que veda ao Estado todo tipo de tratamento discriminatório arbitrário. Cria, também, obrigações concretas para o Poder Público agir no sentido de reduzir as desigualdades de fato existentes na sociedade por meio de políticas públicas e leis que atendam as especificidades dos grupos menos favorecidos.

Tais políticas justificam-se em função dos objetivos fundamentais da República através da construção de uma sociedade livre, justa e solidária; redução das desigualdades sociais e regionais, e a promoção do bem comum. Além disso, a $\mathrm{CF} / 88$ estabeleceu, ela própria, em alguns de seus dispositivos, um tratamento diferenciado a determinados grupos vulneráveis, como quando instituiu a proteção do mercado de trabalho da mulher, a reserva de percentual de cargos e empregos públicos para as pessoas com deficiência, além de ter valorizada explicitamente a contribuição indígena e afro-brasileira a cultura nacional.

\footnotetext{
${ }^{21}$ Gomes (2000, p. 87).

${ }^{22} \mathrm{O}$ princípio da igualdade formal vem expressamente previsto no art. $5^{\circ}$, caput, da $\mathrm{CF} / 88$. Já o princípio da igualdade material constitui o fundamento dos objetivos sociais previstos no art. $3^{\circ} \mathrm{da} \mathrm{CF} / 88$, dos direitos sociais previstos nos arts. $6^{\circ}, 7^{\circ}$ ao 11 e no Título VIII que trata da "Ordem Social”.
} 
Tais objetivos e valores só se realizam por meio de políticas promocionais que combinem redistribuição e reconhecimento.

Vale dizer que as discriminações em sentido positivo estabelecidas pela $\mathrm{CF} / 88$ não são taxativas. A $\mathrm{CF} / 88$ não vedou a adoção de outras diferenciações, desde que plenamente justificadas. Assim, não é correto afirmar que as políticas de cotas ou outras espécies de ações afirmativas sejam inconstitucionais, pois não previstas expressamente nesse documento. Tampouco que sejam inconstitucionais porque são incompatíveis com o princípio da igualdade em seu sentido formal, previsto no art. $5^{\circ}$, caput. Na realidade a CF/88 acolheu, ao mesmo tempo, o princípio da igualdade formal e material. Resta saber quando as discriminações são aceitáveis, ainda que não previstas explicitamente na $\mathrm{CF} / 88$, sem que viole o princípio da igualdade de todos perante a lei. As discriminações são recebidas como compatíveis com a cláusula da igualdade apenas e tão somente quando existe um vínculo de correlação lógica entre a peculiaridade diferencial acolhida por residente no objeto, e a desigualdade de tratamento em função dela conferida, desde que tal correlação não seja incompatível com interesses prestigiados na Constituição ${ }^{23}$.

Se as discriminações positivas são estabelecidas juntamente para realizar os valores e objetivos fundamentais previstos na $\mathrm{CF} / 88$, estamos no caminho para defender a sua constitucionalidade, pelo menos em abstrato.

Tomando-se o exemplo da adoção das políticas de cotas nas universidades, ela promove abertura desta instituição à diversidade e à pluralidade, com a inserção de crenças, tradições e valores culturais de grupos tradicionalmente excluídos, como os negros e povos indígenas. Contribui, assim, para a democratização do acesso ao ensino superior, conferindo maiores possibilidades de ascensão social a grupos vulneráveis e minorias e a democratização do acesso aos postos de poder existentes na sociedade.

De fato, é possível afirmar que a adoção de políticas de ação afirmativa está em consonância não apenas com a ordem constitucional brasileira, como com a ordem internacional. Constituem medidas necessárias para se atingir a justiça social e o reconhecimento do direito a diferença, aliviando a carga de um passado discriminatório e fomentando ao presente e no futuro transformações sociais necessárias. Como são mediadas de exceção, elas devem ser transitórias e prever mecanismo de revisão periódica de seus resultados, pois só se justificam se servirem para alcançar objetivos concretos de redução de

${ }^{23}$ Mello (2001, p.17). 
desigualdade sociais e combate aos mecanismos de exclusão fruto de práticas culturais que aniquilam o direito a diferença.

\title{
9 POVOS INDÍGENAS E DIREITOS DIFERENCIADOS NA AMÉRICA LATINA
}

Falar de povos indígenas, no Brasil, é falar de séculos marcados pela violação de direitos, incompreensão das diferenças e negação da diversidade, ao longo dos quais diversas etnias tiveram as terras espoliadas e a autodeterminação violada. Para não referir o genocídio/ etnocídio ${ }^{24}$ praticado, indiscriminadamente, pelos colonizadores externos e internos, usando das mais diferentes estratégias. ${ }^{25}$

A discussão acerca de direitos indígenas compreendendo os sistemas jurídicos de povos indígenas, no Brasil, ganhou novos contornos a partir da Constituição de 1988, especialmente, por deixar evidente que se deve levar a sério a diversidade cultural, rompendo, pelo menos na "inscrição" com o descompromisso político institucional.

A atual Constituição, ao reconhecer aos povos indígenas o direito à organização social, costumes, línguas, crenças e tradições, afirmou o direito dos povos nativos à diferença, forjado pela existência de diversidades culturais, rompendo o paradigma da integração e da assimilação que até então dominava o ordenamento jurídico brasileiro. (ARAÚJO, 2006). Para Luciano:

\begin{abstract}
A conquista histórica dos direitos na Constituição promulgada em 1988 mudou substancialmente o destino dos povos indígenas do Brasil. De transitórios e incapazes passaram a protagonistas, sujeitos coletivos e sujeitos de direitos e de cidadania brasileira e planetária. (2006: p. 19)
\end{abstract}

No entanto, quanto ao direito dos povos indígenas de manter seus próprios sistemas de justiça ou, em outras palavras, seus próprios Direitos ainda não houve a quebra dos antigos padrões; o presente guarda continuidades com o passado, no qual a ordem institucional e jurídica subjugava os povos indígenas. Hoje, como antes, os direitos diferenciados dos povos indígenas não são respeitados.

\footnotetext{
${ }^{24}$ Compreende-se genocídio como ódio étnico-racial que produz etnocídio, tomado aqui como ações intencionais (ou supostamente não-intencionais) que destroem a cultura de um povo em função das tentativas de "integração" e/ou "assimilação" que pode ou não ser secundada por atos de violência que conduzem ao extermínio físico dos membros de um determinado grupo étnico-racial. Ambos os conceitos são utilizados para descrever os processos de colonização Impostos; pelos europeus, aos povos indígenas e tribais na América Latina e na África.

${ }^{25}$ Sobre o assunto consultar a obra clássica de RIBEIRO, Darcy. Os índios e a civilização - a integração das populações indígenas no Brasil moderno. Rio de Janeiro, Civilização Brasileira, 1970.
} 
No Brasil, ainda que a legislação infraconstitucional através do Estatuto do Índio 26 "tolere" para utilizar a expressão da lei, através da aplicação das normas indígenas ${ }^{27}$ de forma secundária quando a lei for omissa ou inferior desde que não contrarie as normas estatais, os tribunais, conforme observa Souza Filho (2006), mesmo em delitos praticados dentro das terras indígenas e entre indígenas, têm-se considerado pertinentes para o julgamento. Afinal, direitos não podem ser tomados via tolerância, devem ser respeitados sempre!

Em outros países da América Latina, a situação dos povos indígenas não é diferente do que ocorre no Brasil. No caso do Paraguai a situação que se pretende analisar no momento apesar do reconhecimento de direitos formais pela Constituição, as violações das formas de vidas diferenciadas e dos próprios sistemas jurídicos desses povos são constantes.

O Direito, assim como a lei, é uma construção histórica, resultado da atividade humana e, nesse sentido, sujeito às lógicas da história e do poder, constituindo-se, desse modo, em espaço privilegiado de manobras, isto é, de inclusão versus exclusão, de legitimidade versus ilegitimidade, de Direitos versus usos e costumes (direito consuetudinário). Criam-se, assim, discriminações jurídicas, manifestações do colonialismo interno e das constantes tensões entre colonizadores e colonizados, espaço em que o estatal é hegemônico diante do não estatal. Nesse sentido, o uso de expressões tomo direito consuetudinário, usos e costumes ou resolução alternativa de conflitos de nenhuma maneira assegura a real coexistência de Direitos em situação de igualdade; ao contrário, ao dizer que as formas de jurisdição e administração de justiça são válidas sempre que não sejam contrárias à Constituição ou às leis limita-se a inclusão do Direito indígena e predefine-se o controle e a subordinação. Nas entrelinhas o Estado expressa monopólio da norma jurídica, mostrando quão longe se está do autêntico pluralismo jurídico, uma vez que mantém o direito indígena subordinado ao direito estatal. O colonialismo jurídico a que estão submetidos os povos indígenas demonstra a incapacidade de coexistência na diversidade, tanto política como social e jurídica.

Apesar do reconhecimento formal da diferença dos povos indígenas na Constituição brasileira, a violação de direitos ainda se faz sentir e as situações de fricções

\footnotetext{
${ }^{26}$ O projeto referente ao novo Estatuto do Índio tramita no Congresso nacional há mais de 21 anos. Aliás, é hora de pensar em criar um Estatuto dos Povos Indígenas com a participação dos interessados, assim se evitariam as equivocadas interpretações do estatuto que mesmo vigente foi "anulado" pela Constituição brasileira de 1988.

${ }^{27}$ Diz o Estatuto do índio: "Art. 57. Será tolerada a aplicação, pelos grupos tribais, de acordo com instituições próprias, de sanções penais ou disciplinares contra os seus membros, desde que não revistam caráter cruel ou infamante, proibida em qualquer caso a pena de morte" Conferir: BRASIL. Lei Nº. 6.001/1973. Disponível em
} 
interjudiciais $^{28}$ se fazem presentes no cotidiano Latino Americano. A expressão refere-se à contraposição do Direito indígena ao Direito estatal, sob o "sistema interétnico" forjado pela tensa convivência entre duas populações vinculadas por interesses diametralmente opostos; para Moreira (2005), a insubordinação do Direito indígena revela a instabilidade do sistema.

Mostra-se, no entanto, que existem mecanismos internos e/ou externos que garantem a efetivação da diferença não como desigualdade, e sim como oportunidade de autodeterminação desses povos, especialmente pela capacidade de mobilização do movimento indígena.

No Estado do Amapá, especialmente na cidade de Macapá observa-se que as relações trabalhistas estabelecidas com os índios desde a colonização do século XVI, demonstram o caráter aniquilador, explorador e até mesmo escravocrata. O Estado manteve-se por muito tempo inoperante diante das populações indígenas. Mesmo sabendo da sua existência, as políticas voltadas para essas populações sempre foram de natureza integracionista, tendo esta proposta o objetivo de assimilar o elemento indígena à sociedade envolvente, até o seu total desaparecimento do território brasileiro, tendo o seu ápice com a promulgação da Lei 6.001/73 - Estatuto do Índio. Este cenário vem a mudar com as pressões políticas internas e externas a partir da década de 70, que foram intensificadas nos anos 80 com a publicação da Constituição em 1988, perpassando pela Convenção da OIT, de n 169 , ratificada no Brasil, pela Câmara dos Deputados. No Senado Federal, depois da aprovação pela Comissão de Constituição, Justiça e Cidadania, em dezembro de 2000, aguarda inclusão na ordem do dia para votação em plenário.

O pluralismo jurídico, a partir dos teóricos trabalhados nesta dissertação permite que se tenha urna compreensão da existência do outro e de suas diferenças, partindo de uma reflexão de alteridade. Nesta direção, há de se respeitar a concepção de mundo do outro e, mais especificadamente, da relação de trabalho que pode e está sendo estabelecida entre diversos atores sociais, afim de que o Estado possa, em conjunto com os povos indígenas, estabelecer legislação trabalhista que resguarde as especificidades no mercado de trabalho.

\footnotetext{
${ }^{28}$ Conforme explica Moreira (2005), o conceito de "fricção interjudicial" foi inspirado no conceito de "fricção ínterétnica" de Cardoso de Oliveira (1972). Segundo este autor, fricção interétnica refere-se ao "... ao contato entre grupos tribais e segmentos da sociedade brasileira, caracterizados por seus aspectos competitivos e, no mais das vezes, conflituosos, assumindo esse contato muitas vezes proporções 'totais; i. e., envolvendo toda a conduta tribal e não-tribal que passa a ser moldada pela situação de fricção interétnica" (1972: 128. Grifos no original.) Conferir: CARDOSO OLIVEIRA, Roberto. O índio e o mundo dos brancos. Uma interpretação sociológica da situação dos Tukúna. 2a ed. São Paulo, Livraria Pioneira Editora, 1972.
} 
A Conferência Geral da OIT foi convocada em Genebra pelo Conselho Administrativo da Repartição Internacional do Trabalho e tendo ali se reunido a 7 de junho de 1989, pelo que se tem evidenciado, à medida que a sociedade se desenvolve e multiplica os sujeitos emergentes, consequentemente aumenta os ordenamentos em razão da multiplicidade das relações.

Inclusive, isso pôde ser vislumbrado a partir das entrevistas realizadas, sobretudo, o modelo já introduzido na aldeia Kumarumam, dos Galibi-Marworo. O Estado democrático de direito consagra o pluralismo jurídico pelo fato de não ser o Estado o único a editar normas.

A democracia é exercida com base na existência de várias normas jurídicas, oriundas também das partes envolvidas, inclusive para regular as relações de trabalho. Mas, a contemporaneidade do Estado democrático de Direito não mais autoriza atitudes autoritárias e corporativas como as contidas na CLT, a qual regula minuciosamente as condições de trabalho estando, portanto, desatualizada, tendo em vista as mudanças ocorridas (intensificação do capital) com a globalização, as novas tecnologias e os novos paradigmas.

O que se pode observar na Legislação Nacional é que a maioria das regras trabalhistas está determinada na Lei, na norma estatal que é excessivamente protetora e detalhista, devendo portanto, haver maior espaço para a regulação das relações de trabalho, sobretudo, quando envolve os indígenas esta perspectiva, o direito do trabalho autoriza que a fonte de normas jurídicas pode ser a vontade das partes, a norma decorrente do direito internacional e os usos e costumes, oriundos, neste caso, das comunidades indígenas. Há portanto, um campo muito grande aplicabilidade da norma trabalhista.

No verdadeiro estado democrático de Direito as normas são elaboradas com a mais ampla participação possível, nesse caso, dos indígenas, admitindo, a coexistência de várias normas. Evidente, no entanto, que o Estado há de intervir na área trabalhista para assegurar normas de ordem pública. É necessário que o Estado garanta os direitos democráticos, mas também deva se adaptar ao pluralismo de normas trabalhistas; devendo sistematizar as normas oriundas dos grupos indígenas.

O direito nasce do fato e não o contrário. A Amazônia, neste contexto, é o cenário que reflete os fatos para a academia, justificando, portanto, a elaboração de uma legislação trabalhista especial para os indígenas, levando em conta suas especificidades. Assim, cabe ao Estado perceber e regular, sem menosprezar a existência, as vontades e os desejos dos indígenas, sendo estes a presença imprescindível nesse diálogo. 
A partir da ordem constitucional vigente, observa-se o reconhecimento das populações indígenas, sua organização, costumes, língua e tradição. Entretanto, não se percebe a partir das pesquisas de campo e do contato com as organizações indígenas nacionais e internacionais (CIMI, APIO, APITU, AGM, COICA), a existência de uma legislação trabalhista que resguarde os elementos do Artigo 231 da Constituição Federal Brasileira.

Conseqüentemente, esta existência está ainda a depender de um porvir, Também, o que se pôde observar é que apenas questões imediatas, o ponto de vista do Estado, estão sendo discutidas (saúde, educação e terra), como se a relação de trabalho não estivesse inseri da na vida do índio e não fosse tema relevante. Tem-se o agente indígena de saúde, o professor indígena, além das relações jurídicas estabelecidas, a partir da legislação.

Então, como se falar em reconhecimento dos povos indígenas, onde não existe uma legislação apropriada para as questões trabalhistas envolvendo sujeitos indígenas que já fazem parte do mercado de trabalho! A respeito, há, pois, de se avançar na discussão e na definição e implementação de políticas públicas e na proposição de uma legislação específica sobre trabalho indígena.

Nessa perspectiva, o Projeto de Lei nº 2.057/91 - Novo Estatuto das Sociedades Indígenas, já defasado, não aborda em nenhum momento a questão trabalho. O Artigo 10 da Constituição vigente (Brasil, Constituição, 1988) remete à questão da cidadania, dos valores sociais do trabalho e da livre iniciativa e do pluralismo jurídico, dentre outros, itens que por si só autorizam a criação de uma legislação específica voltada para o trabalho. Ressalta-se que não se procurou abordar as conseqüências de uma legislação trabalhista indígena para as ramificações da sociedade, especificamente, para os empresário.

Neste sentido, há de se levar em conta as suas crenças e costumes como o período da pesca, da colheita, das festas tradicionais, dos rituais de luto, um período de férias diferenciado, remuneração proporcional às horas trabalhadas, respeito pelos seus traços culturais em seus postos de trabalho, como direito ao uso de artefatos (pulseiras, pinturas e cordões). Só assim, se estará viabilizando a criação de uma legislação trabalhista especial que atenda os indígenas. 


\section{CONCLUSÃO}

As políticas estatais de caráter universal não tem sido suficientes para a redução da desigualdade social e a exclusão cultural, causando um impacto desproporcionalmente lesivo as minorias e aos grupos vulneráveis, contribuindo para a reprodução e o aprofundamento dos mecanismos de hierarquização existentes na sociedade.

Os objetivos previstos no art. $3^{\mathrm{a}}$ da $\mathrm{CRFB} / 88$, de que são exemplos a erradicação da pobreza e da marginalização e a redução de desigualdades sociais e regionais, só poderão ser atingidos se os Poderes Públicos levaram em conta a diminuição das desigualdades desde os pontos de partidas. Em outras palavras, não adianta esperar os resultados da implementação de uma política pública se as condições para a fruição dos direitos que ela vem garantir não forem oferecidas aos grupos mais vulneráveis.

No entendo, é preciso levar em conta que o status na sociedade pluralista, como diria Fraser, não pode ser reduzido a uma questão de classe. Outros fatores, além da má distribuição dos recursos econômicos, contribuem para um tipo de injustiça como a exclusão por razões de não reconhecimento das diferenças culturais.

$\mathrm{Se}$ o objetivo é combater as desigualdades sociais e promover o reconhecimento do direito à diferença, as políticas universalistas determinadas pelos representantes eleitos pelo povo devem conviver com a implementação de mecanismos de proteção diferenciados que garantem o respeito a grupos vulneráveis, o reconhecimento de sua participação na sociedade em igualdade de condições com os grupos majoritários e a distribuição mais justa dos recursos de poder e bens socialmente produzidos.

Trata-se da dupla dimensão da justiça, segundo a qual somente a redistribuição somada ao reconhecimento produz a realização da igualdade em seu sentido mais amplo, visando maior proteção possível às minorias, em especial aos povos indígenas, assegurando maior efetividade de Direitos àqueles que estiveram em sua grande parcela à margem do processo de desenvolvimento social, político e econômico. 


\section{REFERÊNCIAS}

ARISTÓTELES. Ética a Nicômaco. São Paulo: Editora Martin Claret, 2000. Livro V.1131,a.

ASSIS, Eneida. Escola Indígena, uma "frente ideológica"? Dissertação (Mestrado em Antropologia). Universidade de Brasília, Brasília - DF. 1981

BARRETO, Helder Girão. O índio diante do Sistema Jurídico. In: Revista dos Tribunais do TRF, $1^{\circ}$ Região, Vol. 16, nº 03. mar/2004. Brasília- TRF $1^{\circ}$ Região.p. 13-16.

BARIÉ, Cletus Gregor. Pueblos Indígenas y Derechos Constitucionales en América Latina: un panorama. $2^{\text {a }}$ Ed. Versión eletrônica, 2004.

BOBBIO, N. Igualdade e liberdade. Rio de Janeiro: Ediouro, 1997.

BONAVIDES, P. Do Estado Liberal ao Estado Social. São Paulo: Malheiros, 1996.

COMPARATO, F. K. A afirmação histórica dos direitos humanos. São Paulo: Saraiva, 2003.

DA MATTA, Roberto. Carnavais, malandros e heróis. Rio de Janeiro, Zahar. 1981

FARIA, A. O. Do princípio da igualdade jurídica. São Paulo: Revista dos Tribunais; Editora da Universidade de São Paulo, 1973.

FRASER, N. Reconhecimento sem ética? Lua Nova, n. 70, p. 101-138, 2007.

GOMES, J. B. Ação afirmativa e princípio constitucional da igualdade. Rio de Janeiro: Renovar, 2000.

HABERMAS, J. Direito e Democracia. Entre facticidade e validade. Rio de Janeiro: Tempo Brasileiro, 2003.

HABERMAS, J. A Inclusão do Outro. Estudos de teoria política. São Paulo: Loyola, 2007.

HONNETH, A. Luta por Reconhecimento. A gramática moral dos conflitos sociais. São Paulo: Editora 34, 2003.

LAFER,C. Parecer. O caso Ellwanger: antissemitismo como crime da prática de racismo. Parecer aceito e apresentado no STF na condição de amicus curiae no julgamento do caso Ellwanger. HC 82.424/RS. Revista de informação legislativa, v. 41, n. 162, p.55-58, abr.-jun. 2004.

LOPES, J. R. L. Justiça e Poder Judiciário, ou a virtude confronta a instituição. Revista USP, São Paulo, v. 21, p. 22-30, 1994.

O direito das minorias no mundo globalizado. 2000. Mimeografado.

MELLO, C. A. B. Conteúdo jurídico do princípio da igualdade. São Paulo: Malheiros, 2001. 
PIOVESAN, F. Ações afirmativas da perspectiva dos direitos humanos. Cadernos de pesquisa, v.35, n. 124, p. 47, p. 43-55, jan.- abr. 2005.

SOUSA SANTOS, B. A construção intercultural da igualdade e da diferença. A gramática do tempo: para uma nova cultura política. São Paulo: Cortez, 2010.

SOUZA, Jessé. A construção social da subcidadania: para uma sociologia política da modernidade periférica / Jessé Souza - Belo Horizonte: Editora UFMG; Rio de Janeiro: IUPERJ, 2003

SOUZA, Jessé. A sociologia dual de Roberto da Matta: Descobrindo nossos mistérios ou sistematizando nossos auto-enganos? Revista Brasileira de serviços sociais. V 16. $\mathrm{N}^{\mathrm{o}} 45$ 